\title{
Defined Observation Body Position Code
}

National Cancer Institute

\section{Source}

National Cancer Institute. Defined Observation Body Position Code. NCI Thesaurus. Code $C 93775$.

A coded value specifying the 3-dimensional spatial orientation of a subject during a particular observation. 